\title{
Study of an Electric Energy Generation System from Exhaust Waste Recovery from an Internal Combustion Engine
}

\author{
Jorge de-J. Lozoya-Santos, Jonathan Rivas Torres, Adán Sáenz Herrera, Julio C. Salinas-Maldonado, \\ Eduardo Mariscal Hay, Adriana Vargas-Martínez ${ }^{*}$ \\ Universidad de Monterrey, San Pedro Garza García, México
}

\begin{abstract}
A conventional car engine uses at best about one-third of the fuel combustion energy, while the rest of the energy is lost in friction and most in heat. In the face of the new emission regulations proposed by the government due to the high levels of pollution, and with the aim of achieving cleaner and more efficient transportation, vehicle exhaust gas recovery is being researched in the last years. It is of interest for the automotive industry to recover this wasted energy, thus increasing engine efficiency, reducing fuel consumption and pollution. One way to achieve both objectives is the conversion of engine waste heat to a more useful form of energy, either mechanical or electrical. This paper study a system prototype based on Brayton's thermodynamic cycle driving an Electrical Generator to recover energy from the exhaust gases from a commercial internal combustion engine.
\end{abstract}

Keywords: Exhaust Gas Recovery, Turbocharging, Brayton Cycle Efficiency.

\section{Introduction}

In recent years, OEM's have been put to a big challenge to further reduce the CO2 emission from vehicles [1]. Along with hybridization, improving efficiency and lowering fuel consumption from vehicles equipped with internal combustion engine (ICE) is the main way to achieve it. Since the early beginnings of ICE, constructors have been aware that a big portion of energy is wasted by throwing high enthalpy exhaust gases to atmosphere [2], from a small percentage that could be mostly useful to be used to improve powertrain efficiency. In a typical energy flow path of an internal combustion engine, only $25 \%$ of the fuel combustion is utilized for vehicle operation, whereas about $70 \%$ of the total fuel energy dissipates to the environment as heat loss primarily through the vehicle exhaust system and radiator [3]. Heat available in the exhaust gas of an engine can be an important heat source [4].

\section{Background}

\subsection{Waste Heat Recovery}

Many researchers recognize that Waste Heat Recovery from engine exhaust has the potential to decrease fuel consumption without increasing emissions, and recent technological advancements have made these systems viable and cost effective [5], [6]. A waste heat recovery system has the potential to convert some of this waste heat into electricity and consequently reduce the fuel consumption of the car by driving the alternator with exhaust gas energy, instead of doing it with the mechanical output of the engine [7].

Given the importance of increasing energy conversion efficiency for reducing both the fuel consumption and emissions of engine, scientists and engineers have done lots of successful research aimed to improve engine thermal efficiency, including supercharge, lean mixture combustion, etc. However, in all the energy saving technologies studied, engine exhaust heat recovery is one of the most effective [7].

\footnotetext{
*Adriana Vargas-Martínez. Tel.: +5218119173592

E-mail: adriana.vargas@udem.edu

(C) 2018 International Association for Sharing Knowledge and Sustainability

DOI: 10.5383/ijtee.16.01.007
} 


\subsection{Exhaust Heat Recovery (HER)}

Rankine Cycle EHR (RC-EHR) system comprises of four main components: evaporator/heat exchanger, expander, condenser and circulation pump. With the evaporator/heat exchanger, the working fluid is superheated by absorbing thermal energy provided by the exhaust gas. Flowing out from the evaporator as high temperature steam, the working fluid is driving the expander to produce useful work. The waste steam from the expander is then cooled down through the condenser and returns to liquid form. Finally, the working fluid is pumped to maintain the circulation. It must be noted that the expander is connected mechanically to a generator that charges the battery of the vehicle. Thermoelectric Generator EHR (TEG-EHR) system which comprises of three main components: thermoelectric generator, heat coupler to the exhaust pipe and a cooling coupling to the engine cooling tank. The temperature difference between the hot and cold surfaces of TEG induces a current that may be used for the charging of the battery [3]. Brayton Cycle HER (BC-EHR) system consists of a turbine, a heat exchanger (HE), and compressors in sequence. The use of BC turbine is to fully expand the exhaust gas available from the upper cycle. The remaining heat in the exhaust after expansion is rejected by the downstream heat exchanger. Then, the cooled exhaust gases are compressed back up to the ambient pressure by one or more compressors [8]. There are various technologies for exhaust gases waste heat recovery. Probably, the most investigated technology is the Rankine cycle [2]. Many studies and experimental installations have been done for both light and heavy-duty engines. Johansson and Söderström [9], reviewed thermodynamic cycles for converting waste heat into electricity using thermoelectric generators, organic Rankine cycles and phase change materials with respect to temperature range of the heat source, conversion efficiency, and the organic Rankine cycles has a higher conversion efficiency and longer technical life. Bianchi and De Pascale also compared the electric efficiency of thermoelectric generators, Organic Rankine cycles, Stirling engines and inverted Brayton cycles, and the ORC has the highest efficiency [2]. A big challenge for Rankine cycle application is packaging of expander and heat exchangers (HEs) that need to be big to achieve good efficiency. Brayton cycle has been considered as an alternative technology for recovering heat at intermediate temperature applications in industrial areas [10]. The Brayton cycles are a mature technology and were considered as the most promising power generation system for near future application of the space station [11]. Much of the required equipment and technology for the Brayton cycle is available and this system has a good potential for multiple starts as well as for achieving required long-time reliability [12]. The Brayton cycle considered as a potential exhaust-gas heatrecovery system has not been fully studied, especially when applied to light-duty automotive engine. In this paper, this application was studied.

\subsection{The Brayton Cycle}

The Brayton cycle is the basis of the cyclic gas turbine [13]. In this cycle, air and fuel pass across the single control surface into the compressor and combustion chamber, respectively, and the combustion products leave the control surface after expansion through the turbine. Part of the turbine work developed is used to drive the compressor, while the remainder is available to generate electricity [14]. In the closed cycle, a heat exchanger adds heat to the fluid, which is provided by an external heat source. The fluid is cooled down in another heat exchanger after it leaves the turbine and before it enters the compressor. Although the cycle is usually run as an open system (and indeed must be run as such if internal combustion is used), it is conventionally assumed for the purposes of thermodynamic analysis that the exhaust gases are reused in the intake, enabling analysis as a closed system. The ideal Brayton cycle consists of four processes: Isentropic compression process, isobaric combustion process, isentropic expansion process and isobaric cooling process. On the other hand, the Real Brayton Cycle compression is not completely isoentropical, but politropical, and this is due to friction losses mostly. Heating is not isobarical, also due to friction losses within the Heater. Expansion is also politropical. Cooling is polibarical. Every one of these four portions of the cycle may take place in a single stage, or in multiple stages, which can be accommodated to achieve efficiency improvement. Having a larger enclosed area on the same diagram implies larger efficiency for the same cycle, so by multiplying the stages on each sector of the cycle, an interpolation can be obtained as can be seen in Fig. 1.

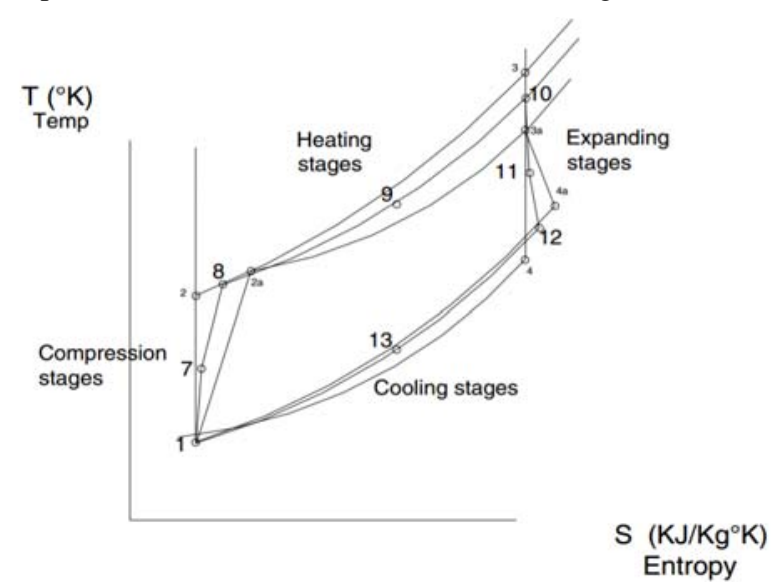

Fig. 1. Multistage Real Brayton Cycle [4].

Using two compression stages [6], with the same hardware efficiencies, we go from 1 to 7 and to 8 instead of from 1 to 2a, enhancing the enclosed area. Likewise heating from 8 to 9 to 10 , instead of 2a to 3a. Using two turbine stages, from 10 to 11 to 12, instead of 3a to 4a. And accordingly, from 12 to 13 to 1 instead of 4 a to 1 .

\section{Proposal}

The main proposal is to develop a system using the efficiency of the thermodynamic Brayton Cycle, which consist of a turbocharger system to compress air and boost the induction of the internal combustion engine, to increase its efficiency. Also, convert the heat energy of the exhaust into mechanical work, to drive the turbocharger and in turn, drive the alternator. The system considers minimal implementation costs by using commercially available automotive components. The electrical part will be simulated; therefore, the mechanical part will be instrumented to introduce it in the simulation of electric power generation of the system as seen in Fig. 2.

The operation of the system starts when the engine reaches its heating temperature, begins to move the turbine thanks to the mass flow of the exhaust gases, exactly in this area, there is a sensor to see the temperature at which the gases reach. After that the gases enter the turbocharger where the mechanical energy is produced and where another RPM sensor is located (at the output of the large turbine). At the exit of the turbocharger we have compressed air where there is also a pressure sensor and we will use to feed the air intake of the engine and give it more power. The three sensed parameters are connected to a data acquisition system where they will be analyzed by means of a 
design of experiments to perform simulations in an arrangement of an alternator charging a battery.

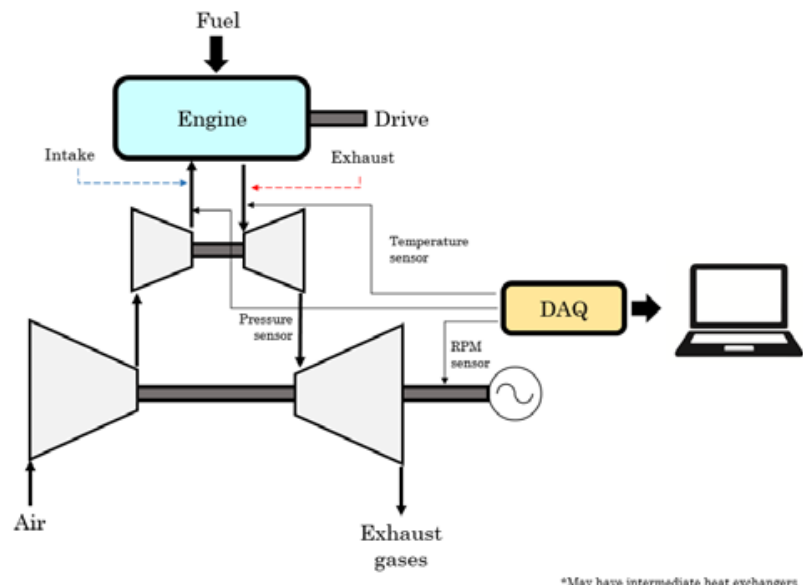

Fig. 2. Diagram representation of the proposed system.

\section{Methodology}

\subsection{Specification}

Before designing the system, it is necessary to define the main components to be used. The system consists of an internal combustion engine and a turbocharger. In the realization of the system components from a previous project were used [4].

\subsection{Design}

Throughout the development of the project design is used for certain components of the system. For the mechanical design, the design of a structure capable of supporting the integration of all components, and resistant to all efforts by the engine vibrations was needed. Also, the design of the fixtures for all sensors and models of each sensor were implemented. For the data acquisition, a new program in Lab View to measure the study parameters which in this case are the temperature at the exit of the exhaust of the engine, the pressure at the inlet engine air, and the revolutions at the output of the large turbine which is where the power would be produced was designed. For the design of experiments certain tests with certain number of iterations each one, to find a general or average behavior of each test and assume that it is the one that plays in each environment were realized. For the design of the simulation the models will be adapted to the parameters of our study, which in this case are the pressure, the temperature, and most importantly, the revolutions per minute produced. The main objective is to see the mechanical work produced by the exhaust gases of the internal combustion engine, so the most important parameter in the graphics must be the revolutions per minute that will be reflected in the simulation of the battery charge.

\subsection{Implementation}

After considering all the components included in the system, analyze their location, the materials used, and how to mount them to the system. It will be possible to perform an integration of all the components, both mechanical, electronic and software, to have a system as a result. First, the integration of the entire mechanical system including a lubrication system for the turbine will be carried out, then an instrumentation will be made to the system, and finally the software design will be integrated to test the operation of the integrated system and verify that it really works.

\subsection{Testing}

For the tests, scenarios of a conventional car will be designed to have real results of electric power produced by an internal combustion engine in parts of a real driving cycle.

\subsection{Simulation}

In this experiment a model of an alternator charging a battery to see results of the system is used. The components for the electrical part could not be defined because the gearbox did not get the expected revolutions. The main point of simulation is to be able to define the rest of the components depending on the electrical power produced by the current system.

\section{Development}

\subsection{Specification}

The first main component defined was the internal combustion engine and for that a Mini BAJA engine from a SAE competition that was in the automotive design engineering laboratory of the University of Monterrey and that had the required specifications by the SAE was used [15] (Fig. 3 (a)). The main characteristic is specified in the Baja SAE Rules as a Briggs \& Stratton $10 \mathrm{HP}$ OHV Intek and so the engine meets this requirement motor, and specifically is a 205400 model and have the general characteristics shown in Table 1 . The second component was a Borg Warner R2S16, two stage turbo chargers used in 4 (Fig. 3 (b)). The other components were defined to record all the relevant parameters, and this includes all the instrumentation. Texense sensors (FPS-V2-10, RS-M10WS, Uxcell K Type) and a NI Data acquisition device (NI-DAQ, USB-9162 with a NI9213 thermocouple input module) were selected.
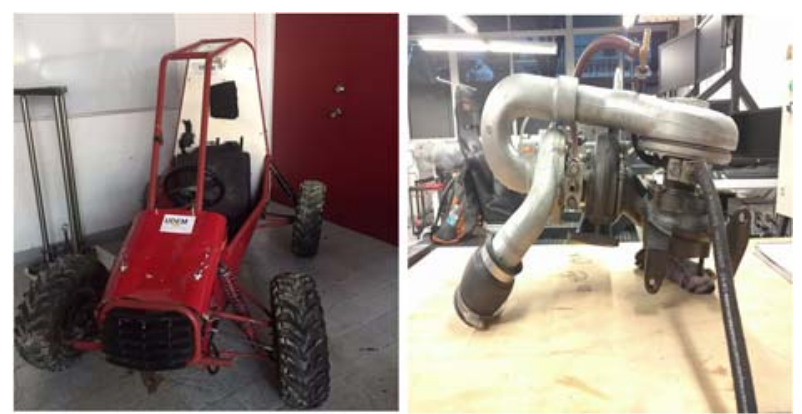

Fig. 3. (a) Mini BAJA UDEM model, (b) Borg Warner RS2 model.

The rest of the components of the project are composed of bulk material, such as piping, metal profiles, hardware, hoses, and software such as Inventor for CAD, Lab View for data acquisition, and MATLAB for data processing. For the implementation of the system a list of components and software was made, and the assembly was carried out.

\subsection{Design}

Throughout the development of the project mechanical design was used for certain components and others were manufactured directly as the connections between the engine and the turbine, but the project design includes hardware and software also. 
Table 1. Briggs \& Stratton specification sheet of 20000 models

\begin{tabular}{ll}
\hline Model 20000 & $15.63 \mathrm{ci}(305 \mathrm{cc})$ \\
\hline Displacement & $3.120 \mathrm{in}(79.24 \mathrm{~mm})$ \\
Bore & $2.438 \mathrm{in}(61.93)$ \\
Stroke & $26-28 \mathrm{oz}(.77-.83 \mathrm{~L})$ \\
Oil Capacity & SAE 30 \\
Gear Reduction Oil Type & $12 \mathrm{oz}(.35 \mathrm{~L})$ \\
Gear Reduction Oil Capacity & $.030 \mathrm{in}(.76 \mathrm{~mm})$ \\
Spark Plug Gap & $180 \mathrm{lb}-\mathrm{in}(20 \mathrm{Nm})$ \\
Spark Plug Torque & $.008-.012 \mathrm{in}(.20-.30 \mathrm{~mm})$ \\
Armature Air Gap & $.004-.006 \mathrm{in}(.10-.15 \mathrm{~mm})$ \\
Intake Valve Clearance & $.004-.006 \mathrm{in}(.10-.15 \mathrm{~mm})$ \\
\hline Exhaust Valve Clearance &
\end{tabular}

Previously studied the behavior of the Brayton cycle in the conditions of the application was first designed using a structure that was able to perform with the heavier assembly that is the assembly of the engine and the turbine in a position where it was able to design connections for the inlet and air outlets of the motor. Fixtures and sensors were also designed and modeled respectively. First, the available 3D models of the sensors were obtained, and the rest were modeled to be able to carry out the design of the fixtures. Some sensors such as the exhaust gas temperature did not require fixture design, because it was mounted on a thread. For this only a manufacturing process was performed to obtain the threading. For the manufacturing process, a work from selection of materials to the construction of the designs (structure, sensors and fixtures) was done. Also, a software design was implemented. Firstly, for the acquisition of data, we created a new program in Lab View to measure our study parameters which in this case were the temperature at the exit of the exhaust of the engine, the pressure at the inlet engine air, and the revolutions at the output of the large turbine which is where the power would be produced (Fig. 4).

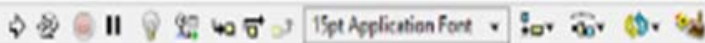

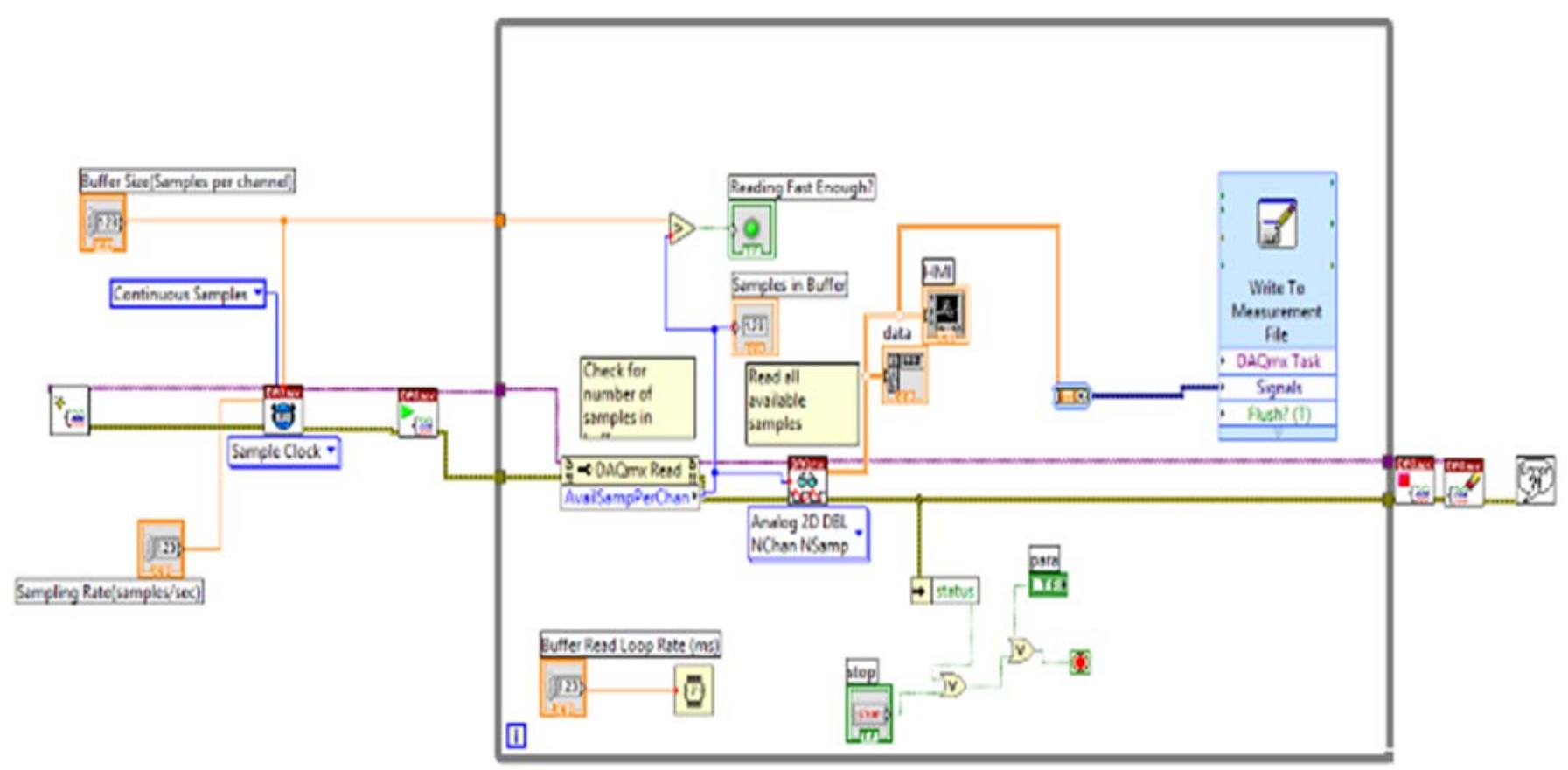

Fig. 4. Labview program for instrumentation.

The other software design was for the processing data in MATLAB. To validate the work as a generator, a simulation of the energy production was realized. For that, a model available in the library of Simulink of an alternator charging a battery [17] was used. This example shows how alternator behavior can be abstracted to a DC model that simulates efficiently. The model captures the increase in stator resistance as the alternator heats up, this reducing device performance. The objective of this model was to simulate the data obtained in the assembly together with the components that could not acquire to see the approximate behavior of the system (Fig. 5).

\subsection{Implementation}

Because of the project, a study station of thermodynamics mounted in the Laboratory of Automotive Design in the University of Monterrey was obtained. Firstly, the setup of all the designs, and all the assemblies necessary for the realization of the tests were implemented. A part of the lubrication of the Electrical Generator from Thermal Solar Energy Project was recycle [4] and that was assemble to the final assembly. After completing all the components, the station was instrumented, and a series of tests were carried out to ensure the correct reading of the sensors. Fig. 6 shows the final mechanic assembly with lubrication system mounted (a) and the instrumentation and complete assembly (b). 


\subsection{Testing}

For testing purposes, three different types of tests were designed, with the objective of evaluating the performance of a conventional motor in specific scenarios with its corresponding energy production. Two-minute tests were designed with three iterations each, where the first test consisted of acceleration and gradual deceleration during the specific time previously. The next test was of gradual acceleration with rapid deceleration and finally, the third test was about acceleration and rapid deceleration in time lapses during the final time.

\subsection{Simulation}

For the analysis of data, a simulation of the alternator charging a battery using a model that was previously mentioned to see the state of charge of the battery by arranging an alternator during the test time lapse was implemented.

In this model, even the efficiency of the alternator is considering the increase in temperature. The model captures the increase in stator resistance as the alternator heats up, this reducing device performance. The resulting graphs show the charge current in amperes (A) during the test time lapse and

are aimed at seeing the difference in the different scenarios to which a conventional car is exposed (see Fig. 7).



Fig. 5. Model of an alternator and a battery in MATLAB [17]
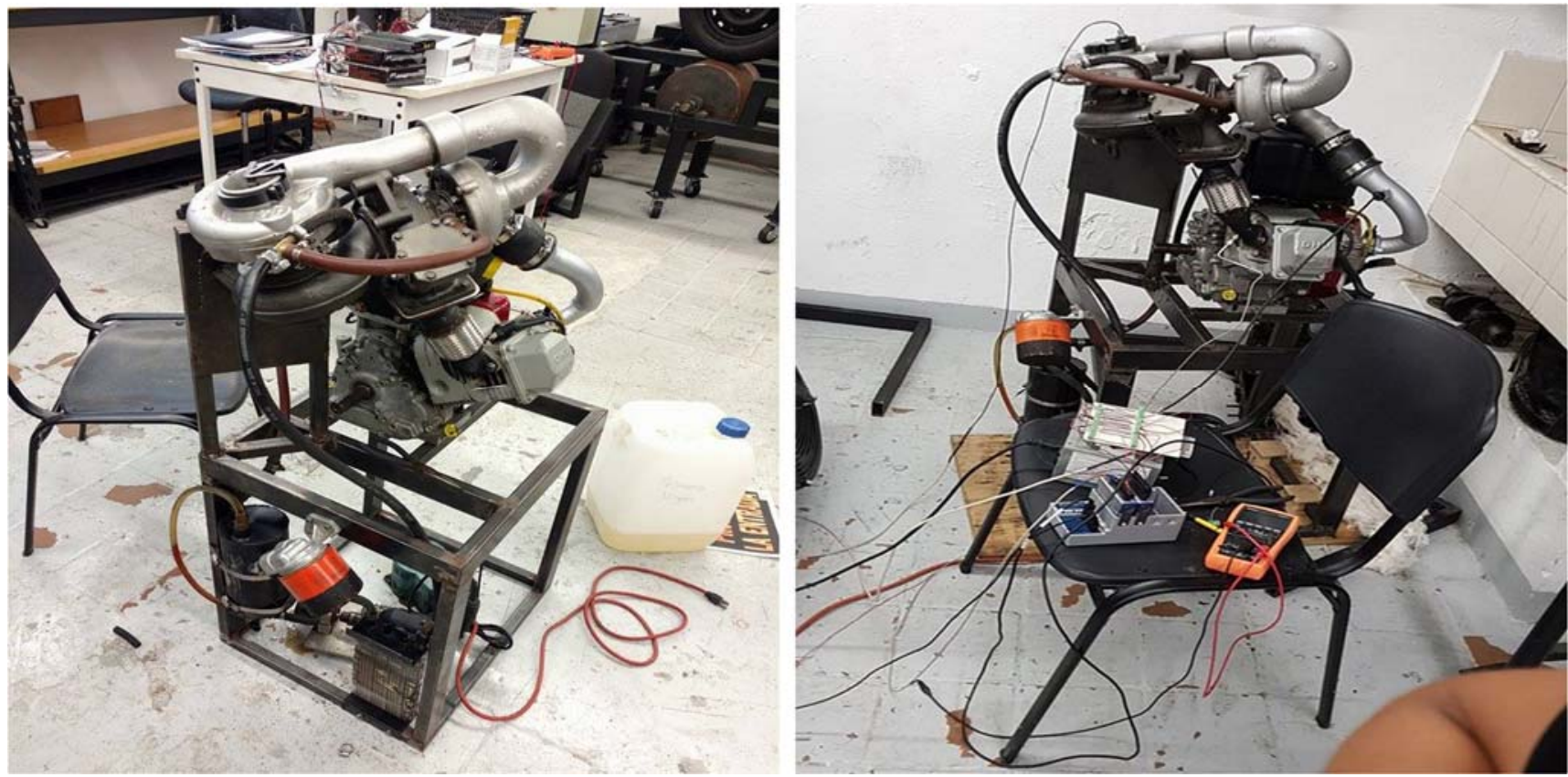

Fig. 6. (a) Final mechanic assembly, (b) Instrumentation and complete assembly. 


\section{Discussion}

As seen in Fig. 6, the prototype system was assembled and ready for test. The tests were performed by the same person, at the same time intervals, with the same iterations every test, to eliminate any possible bias. Obviously, in the graphs of tests a little noise can be distinguish, therefore the signals were filter. As can be seen in Fig. 8, first graph, from 0-60 seconds it is difficult to accelerate with the same slope because at the beginning the throttle increases less RPM. It is easy to identify in the graphs the type of actual acceleration scenario to which it is exposed. Perhaps, adding more scenarios and longer test to obtain clearer conclusions could be done. From Fig. 8, it is observed that the states of charge have a very similar slope, so it could be considered to look for the electrical part with the characteristics of the alternator and battery model.

\section{Conclusions}

First, although the revolutions produced by the motor are not as expected, the simulation shows a charge current in charge absorption, which means that the arrangement works. Second, the study station is indeed functional, so it is possible to perform a deeper analysis with more tests, longer lapses and more iterations with respect to the production of electric energy from exhaust gases from this motor.
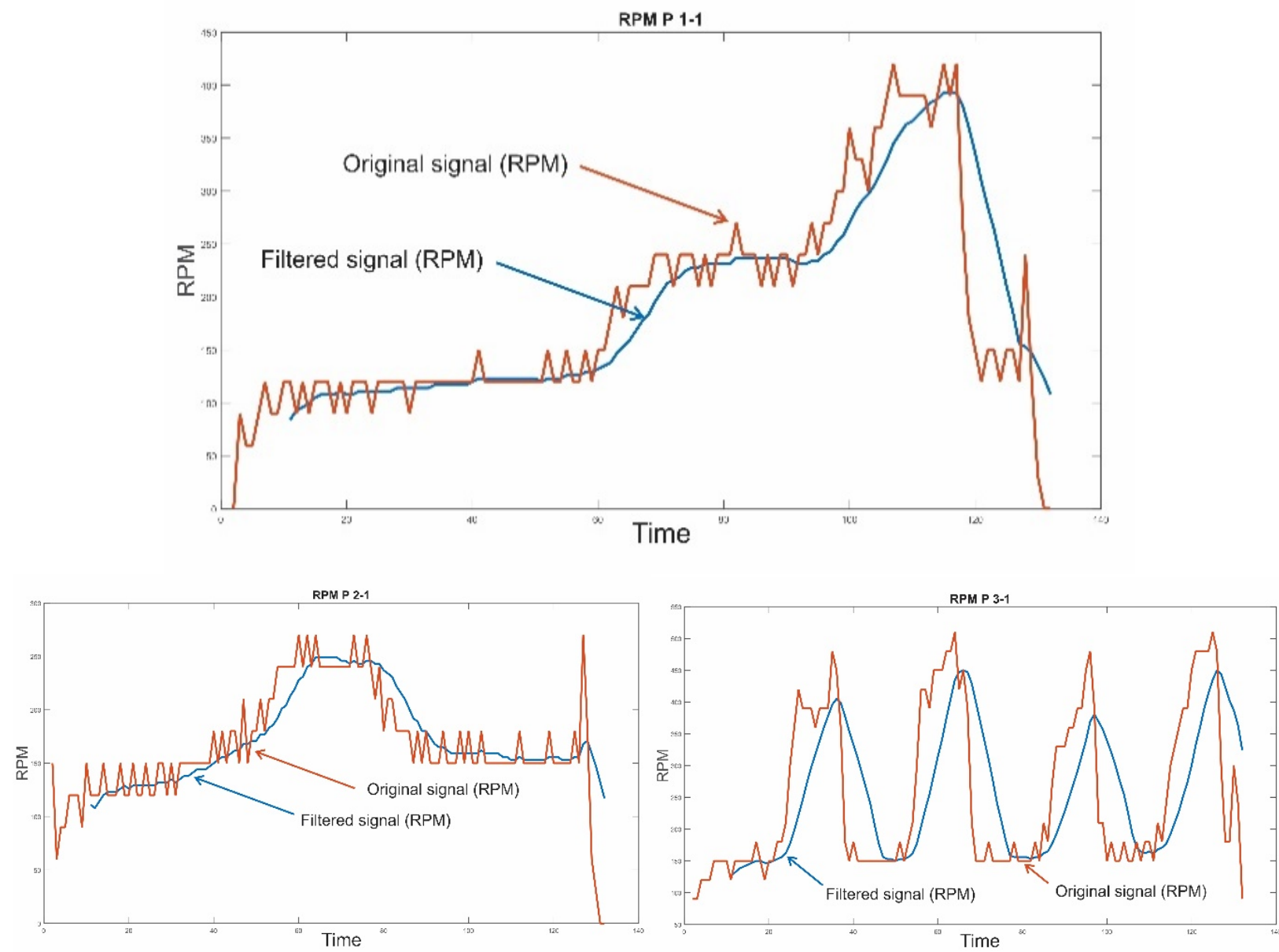

Fig. 7. Final revolutions per minute of the three different tests. 


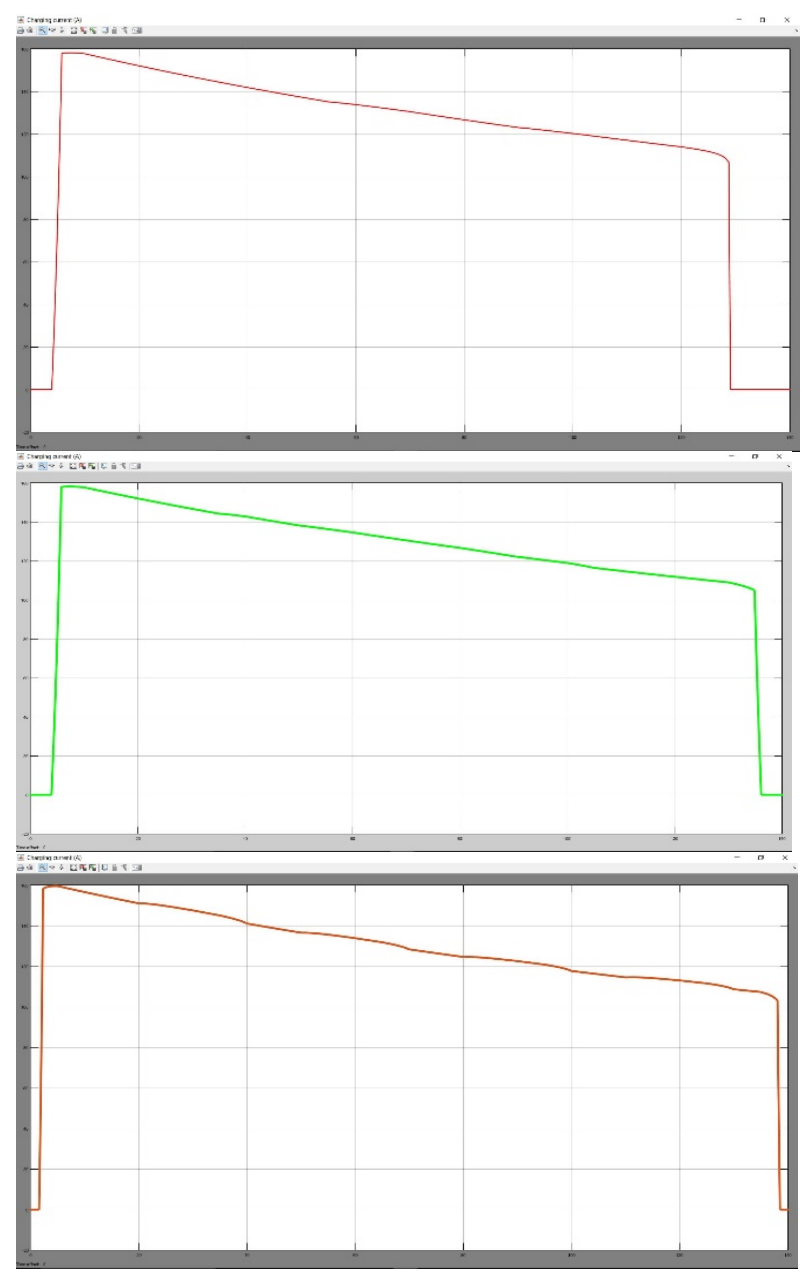

For optimum results and a response closer to a real driving cycle of a car, the recommendation is to work with a larger engine, considering that the work implemented in this project was with a BAJA SAE engine. The selection of the turbocharger must be adequate so depending on the selected engine a previous study must be carried out to choose the one indicated, since it is important that the mass flow produced by the exhaust of the engine is able to start the turbocharger, and in this case, was not enough. The limitations were on project scope, component availability, cost and timing.

The final and most important conclusion is that turbocharging an engine and recovering part of the thermal energy of the exhaust gases to generate electric energy based on the thermodynamic efficiency of a Brayton cycle is feasible with the appropriate components.

Regarding future for the station, it is planned to continue to study its feasibility on a larger scale or to bring our results closer to actual driving cycles, so that in the future it is planned to replace the current Briggs \& Stratton engine with a larger engine of a conventional brand car and it is planned to test the integrated system to a vehicle dynamics simulator [18], with the aim that the simulated acceleration be represented proportionally in the physical system of this article, and thus will be analyzed the production of electric energy in longer and clear driving cycles (Fig. 9).

Fig. 8. Final charge current of each test.

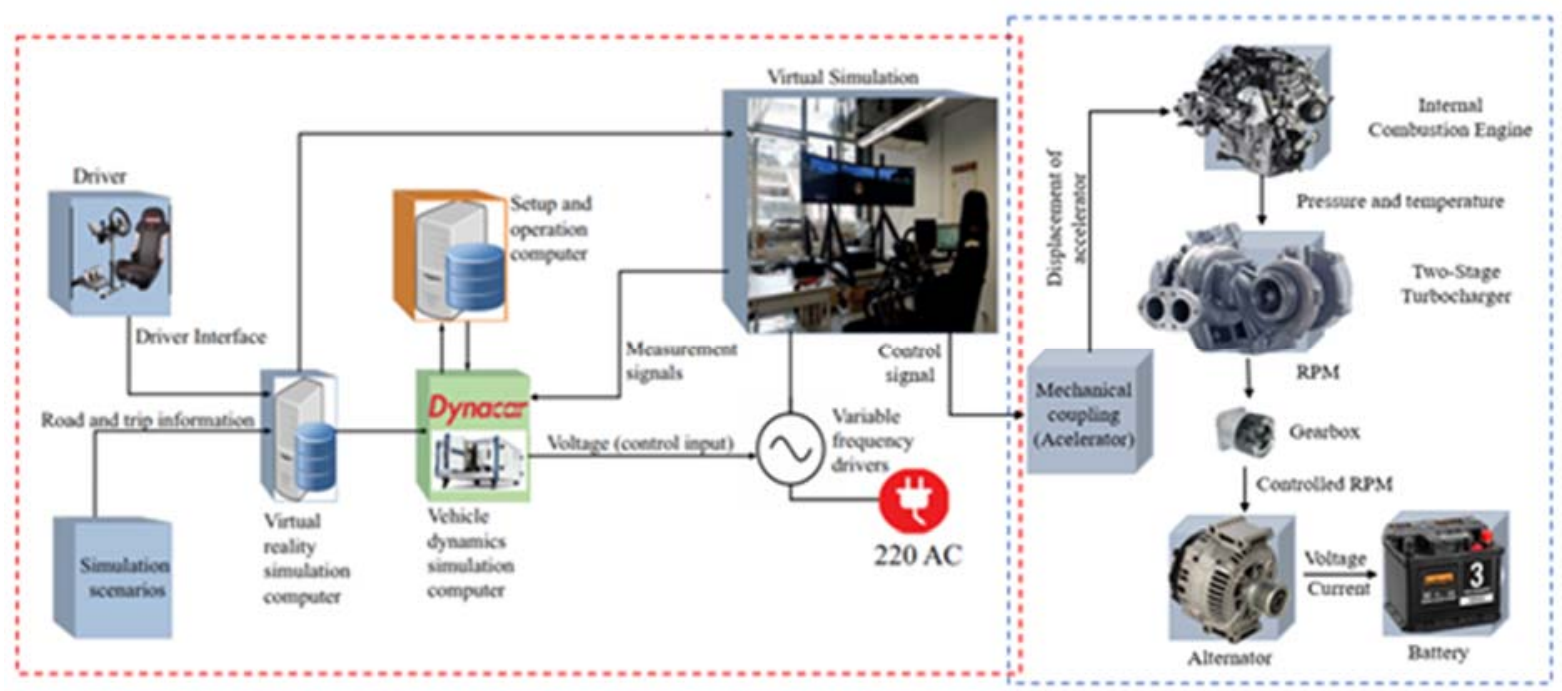

Fig. 9. Integration proposal of a vehicle dynamic simulator [18] for testing of the system. 


\section{Acknowledgments}

All the authors thank to the University of Monterrey for the support during the development of his research.

\section{References}

[1] T. Johnson. Review of vehicular emissions trends. SAE International Journal of Engines. 2015;8:11521167, DOI: 10.4271/2015-01-0993

[2] J. Galindo, J. Serrano, V. Dolz, P. Kleut. Brayton cycle for internal combustion engine exhaust gas waste heat recovery. Advances in Mechanical Engineering, Vol 7(2015). DOI: 10.1177/1687814015590314

[3] E. Avaritsioti. Environmental and Economic Benefits of Car Exhaust Heat Recovery. Transportation Research Procedia, Vol. 14 (2016), pp. 1003-1012. DOI: $10.1016 / j . t r p r o .2016 .05 .080$

[4] S. Hossain, S. Bari, S. Waste heat recovery from exhaust of a diesel generator set using organic fluids. Procedia Engineering, Vol. 90 (2014), pp. 439-444. DOI: 10.1016/j.proeng.2014.11.753

[5] R. Kumutha, A. Sivakumar, S. Abeetha. Investigation of Exhaust Gas Recovery System In SI Engine. Combustion, Vol. 2 (2017).

[6] M. Karvonen, R. Kapoor, A. Uusitalo, V. Ojanen. Technology competition in the internal combustion engine waste heat recovery: a patent landscape analysis. Journal of Cleaner Production, Vol. 112 (2016), pp. 3735-3743. DOI: 10.1016/j.jclepro.2015.06.031

[7] B. Orr, A. Akbarzadeh, M. Mochizuki, R. Singh, R. A review of car waste heat recovery systems utilizing thermoelectric generators and heat pipes. Applied Thermal Engineering, Vol. 101 (2016), pp. 490-495. DOI: 10.1016/j.applthermaleng.2015.10.081

[8] Z. Chen, C. Copeland, B. Ceen, S. Jones, A. Goya. Modeling and Simulation of an Inverted Brayton Cycle as an Exhaust-Gas Heat-Recovery System. Journal of Engineering for Gas Turbines and Power, Vol. 139 (2017). DOI: 10.1115/1.4035738
[9] M. Johansson, M. Söderström, M. Electricity generation from low-temperature industrial excess heat-an opportunity for the steel industry. Energy efficiency, Vol. 7 (2014), pp. 203-215. DOI: 10.1007/s12053-013-9218-6

[10] B. Song, W. Zhuge, R. Zhao, X. Zheng, Y. Zhang, Y. Yin, Y. Zhao. An investigation on the performance of a Brayton cycle waste heat recovery system for turbocharged diesel engines. Journal of Mechanical Science and Technology, Vol. 27 (2013), pp. 17211729. DOI: 10.1007/s12206-013-0422-2

[11] C. Toro, N. Lior. Analysis and comparison of solarheat driven Stirling, Brayton and Rankine cycles for space power generation. Energy, Vol. 120 (2017), pp. 549-564. DOI: 10.1016/j.energy.2016.11.104

[12] Z. Zhang, L. Chen, B. Yang, Y. Ge, F. Sun. Thermodynamic analysis and optimization of an air Brayton cycle for recovering waste heat of blast furnace slag. Applied Thermal Engineering, Vol. 90 (2015), pp. 742-748. DOI: 10.1016/j.applthermaleng.2015.07.057

[13] H. Cunha, K. Kyprianidis. Investigation of the Potential of Gas Turbines for Vehicular Applications. In ASME Turbo Expo 2012: Turbine Technical Conference and Exposition. American Society of Mechanical Engineers, (2012), pp. 51-64.

[14] Y. Cengel, A. Michael, V. Campos Olguín, M. Colli Serrano. Termodinámica. McGraw-Hill, 2003.

[15] S. A. E. Baja. Collegiate Design Series, 2017.

[16] R. Sauerstein, R. Dabrowski, M. Becker, W. Bullmer. Regulated two-stage turbocharging for gasoline engines. BorgWarner Turbo Systems, 2010.

[17] MathWorks, Inc. MATLAB: the language of technical computing. Desktop tools and development environment, version 7, Vol. 9 (2005).

[18] J. Lozoya, J. Salinas, E. Mendez, G. Gonzalez, J. Tudon-Martinez, R. Ramirez-Mendoza. Design and Control of a Mechatronic Vehicle Dynamics Simulator Pitch and Roll Dynamics, (2016), pp. 6772. 